\title{
Fine Structure of Protoplasts of Aspergillus nidulans
}

\author{
By R. K. GIBSON AND J. F. PEBERDY \\ School of Botany and Zoology, University of Nottingham, Nottingham, $N G 72 R D$
}

(Received I9 August 197I; revised 5 May 1972)

SUMMARY

Observations on the ultrastructure of Aspergillus nidulans protoplasts obtained by treatment of mycelium with Streptomyces RA lytic enzyme show that they were free of wall material. The preparations contained two types of protoplasts, released at different times during the lytic enzyme-mycelium incubation. Those released first contained small vesicles and a high density of ribosomes. The type released later had large vacuoles and fewer ribosomes. It is suggested that these differences reflect the hyphal location and origin of the protoplasts.

\section{INTRODUCTION}

There have been several electron-microscopic studies of yeast protoplasts (e.g. Necas, 1964; Havelková, 1966; Streiblová, 1968; Uruburu, Elorza \& Villanueva, I968; Darling, Theilade \& Birch-Anderson, I969) but there are surprisingly few reports on the ultrastructure of protoplasts from filamentous fungi (Manocha, I968; Sagara, I969).

In a previous report (Peberdy \& Gibson, 197I) we described the formation and regeneration of Aspergillus nidulans protoplasts. Examination of the preparations by light microscopy indicated that the protoplasts were free of wall material and that the preparations contained two types of protoplasts. Small non-vacuolate protoplasts were released first during incubation of mycelium in a lytic enzyme and larger vacuolate ones were produced after $3 \mathrm{~h}$. This report deals with an electron-microscopic study of $A$. nidulans protoplasts and confirms the original observations at an ultrastructural level.

\section{METHODS}

Organisms. Aspergillus nidulans strain PI 29, an auxotrophic mutant requiring proline, was maintained on malt extract agar (Oxoid) throughout the investigation. Similar cultures were used for preparing conidial suspensions.

Streptomyces venezuelae RA (Garcia Lopez, Aguirre, Uruburu \& Villanueva, I967), used to prepare the wall-lytic enzymes for the isolation of protoplasts, was maintained on slopes of a mycelium-salts medium based on that of Kuster \& Williams (I964), containing the following $(\mathrm{g} / \mathrm{l}): \mathrm{KNO}_{3}, 2 \cdot 0 ; \mathrm{NaCl}, 2 \cdot 0 ; \mathrm{K}_{2} \mathrm{HPO}_{4}, 0.2 ; \mathrm{MgSO}_{4} \cdot 7 \mathrm{H}_{2} \mathrm{O}, 0.055 ; \mathrm{CaCO}_{3}, 0.02 ; \mathrm{FeSO}_{4} \cdot 7 \mathrm{H}_{2} \mathrm{O}$, 0.0 I; Aspergillus nidulans mycelium, I0.0; agar I $5^{\circ} 0$. The crude lytic enzyme complex, containing chitinase and $\beta \mathrm{I}, 3$ glucanase as its main components, was obtained by concentration of the culture filtrate of $S$. venezuelae RA grown in liquid medium containing chitin (Sigma, London) and laminarin (Koch-Light, Colnbrook, Buckinghamshire) as the sole carbon sources. Methods of preparing the enzyme and Aspergillus protoplasts were described in detail previously (Peberdy \& Gibson, 1971).

Electron microscopy. Protoplasts were washed twice in $0.4 \mathrm{M}-$ mannitol buffered at $\mathrm{pH} 7$ with $0.2 \mathrm{M}$-phosphate buffer. Preliminary observations on the preservation of fine structure 
of protoplasts during fixation resulted in the use of $2 \%$ glutaraldehyde (Taab) supplemented with $0.4 \mathrm{M}$-mannitol buffered at $\mathrm{pH} 7$ for $\mathrm{I} 0 \mathrm{~min}$. Mycelial pellets were washed twice in $0.2 \mathrm{M}$-phosphate buffer and fixed for $20 \mathrm{~min}$ as above. Protoplasts and mycelium were washed twice in $0.4 \mathrm{M}$-mannitol, $\mathrm{pH} 7$, after fixation and post-fixed in $\mathrm{I} \%$ aqueous $\mathrm{OsO}_{4}$ for $3 \mathrm{~h}$. After twice washing the material in $0.4 \mathrm{M}-\mathrm{NH}_{4} \mathrm{Cl}$ in $0.2 \mathrm{M}$-phosphate buffer, $\mathrm{pH} 6$, it was dehydrated by passing through a graded series of ethanol, stained in freshly prepared $\mathrm{I} \%(\mathrm{w} / \mathrm{v})$ uranyl acetate in absolute ethanol for $30 \mathrm{~min}$ followed by two washings in absolute ethanol and embedding in a mixture of methyl methacrylate, butyl methacrylate and styrene I I:3:6 (by vol.) containing I \% (w/v) benzoyl peroxide as catalyst. Blocks were polymerized at $65{ }^{\circ} \mathrm{C}$ for $24 \mathrm{~h}$. Thin sections were cut with glass knives on a Porter-Blum MT 2 ultramicrotome. Sections on grids were stained with lead citrate (Reynolds, 1963) and viewed using an AEI EM 6B electron microscope.

\section{RESULTS AND DISCUSSION}

Electron micrographs demonstrated the lack of walls in protoplasts of Aspergillus nidulans (Fig. I-4), confirming the observations with u.v. fluorescence microscopy reported previously (Peberdy \& Gibson, 197I). Protoplasts were bounded by the plasmalemma which was usually continuous (Fig. 2) or sometimes broken, probably due to distortion during fixation (Fig. I) and either smooth (Fig. 3-4) or corrugated (Fig. 2). The corrugations may also have been caused by distortion during fixation, but as both types were frequently found in single batches of protoplasts it may indicate individual differences in the osmotic sensitivity of the protoplasts. Outpushings of the plasmalemma, similar to those reported by Sagara (I969), were sometimes observed and occasionally these were pinched off to form 'subprotoplasts' (Fig. 9).

Ribosomes were abundant in the cytoplasm of some protoplasts (Fig. 2) and lipid storage granules appeared as large electron-opaque bodies with no limiting membrane (Fig. I, 2). Transparent granules as seen in Fig. I and 4 are possibly glycogen; however, we have no strong evidence to support this interpretation. Sections of one or two nuclei were usually observed in each protoplast. They appeared as circular, ovoid or occasionally irregular profiles with a nucleoplasm often slightly denser than the surrounding cytoplasmic matrix (Fig. 5, 6). Fig. 5 shows more darkly stained regions of nucleoplasm at the periphery of the nuclei. Typical nuclear envelopes were usually seen and were infrequently interrupted by pores, but in some sections the membrane was not visible (Fig. I).

Mitochondria were present in most protoplasts, where they usually took the form of rods (Fig. 2). Cristae were rare, and often were parallel to the long axis of the mitochondrion. Frequently mitochondria took on more abnormal configuration, the most common of which were dumbell-shaped in section (Fig. 4, 6); others appeared hollow or $U$ shaped and may have represented profiles of cup-shaped mitochondria. Observations reporting diversity of mitochondrial form have been reported by many workers (e.g. Kawakami, 196I; Hawker \& Abbott, I963; Hawker \& Hendy, 1963; Moore \& McAlear, 1963; Tanaka \& Yanagita, 1963; Marchant, Peat \& Banbury, I967; Prusso \& Wells, 1967; Campbell, 1970) and may be due to the free movement of these organelles and consequent frequent change of shape (Rouiller, I960).

Endoplasmic reticulum (Fig. 2-4, 10) in the form of tubules and flattened cisternae was sparsely scattered throughout the cytoplasm. Distinction between smooth and rough endoplasmic reticulum was precluded by the density of ribosomes in the surrounding cytoplasm. No Golgi bodies were observed in any protoplast section examined. 


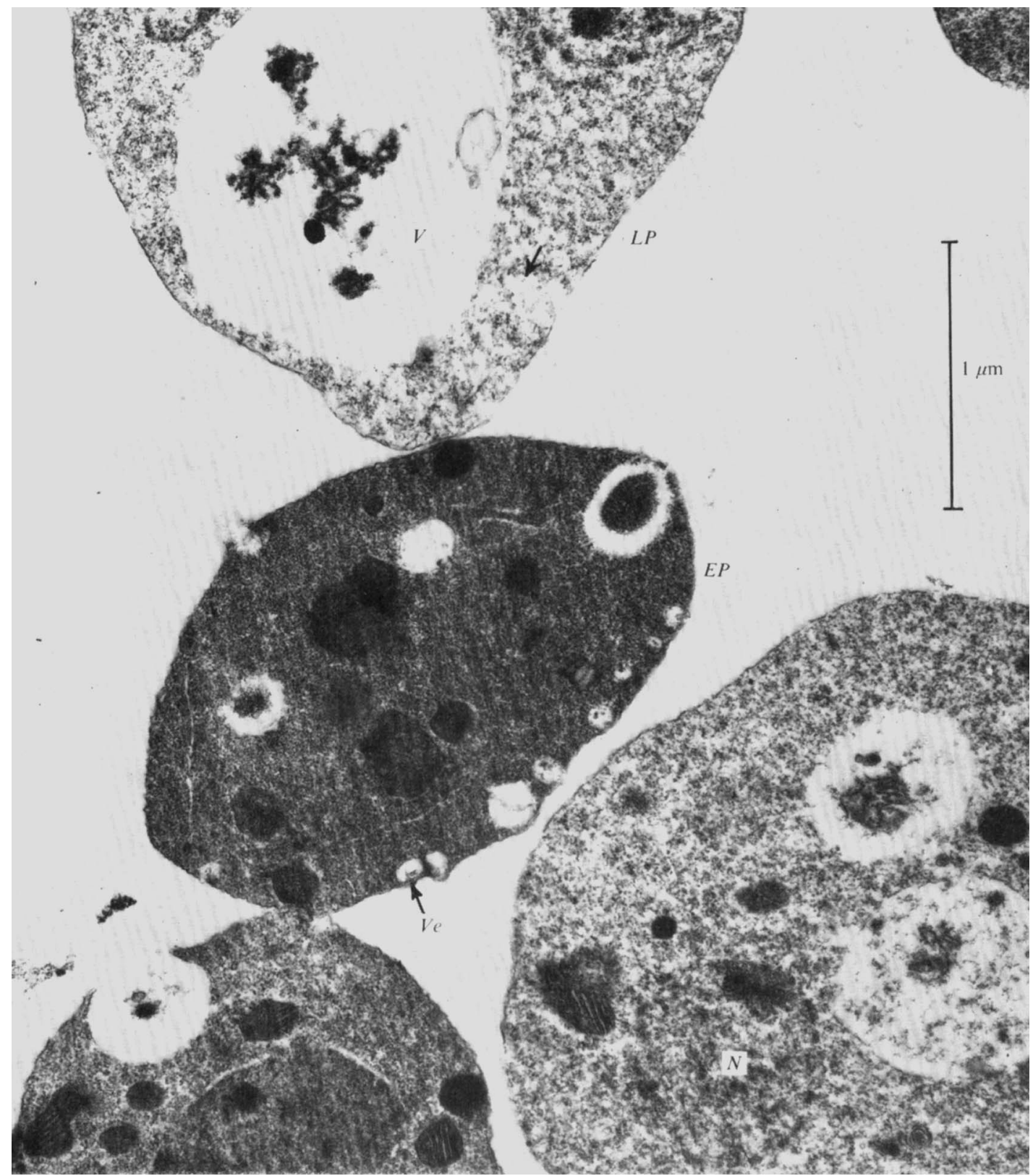

Fig. I to I4. Key to symbols: $C W=$ cell wall; $E P=$ protoplast released during first hour of incubation; $E R=$ endoplasmic reticulum; $L=$ lipid storage granule; $L P=$ protoplast released during second hour of incubation; $M=$ mitochondrion; $N=$ nucleus; $N M=$ nuclear membrane; $P=$ plasmalemma $; R=$ ribosomes; $T=$ tonoplast $V=$ vacuole; $V e=$ vesicle.

Fig. I. Protoplasts released after incubation of mycelium for $2 \mathrm{~h}$ with Streptomyces lytic-enzyme complex. Two types of protoplasts are present: $E P$, small non-vacuolate protoplasts with dense ribosome rich cytoplasm and peripheral vesicles; $L P$, larger vacuolate protoplasts with diffuse cytoplasm, absence of vesicles and presence of transparent granules (arrowed). 


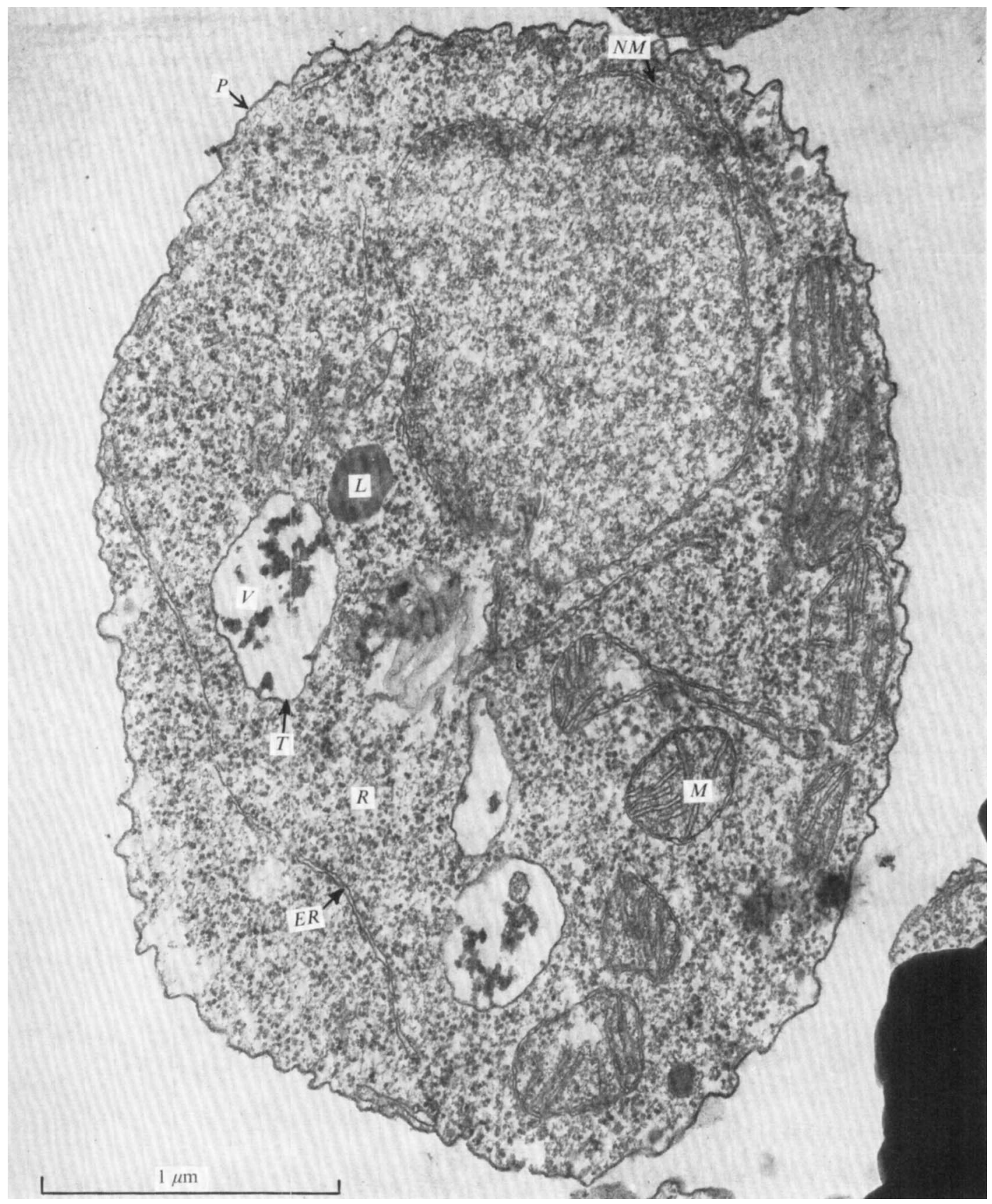

Fig. 2. Protoplast with corrugated plasmalemma and irregular nuclear body. Ribosomes are prominent in the cytoplasm. Presence of small vacuoles and absence of vesicles may indicate that this is a form intermediate between the two types of protoplasts shown in Fig. I. 

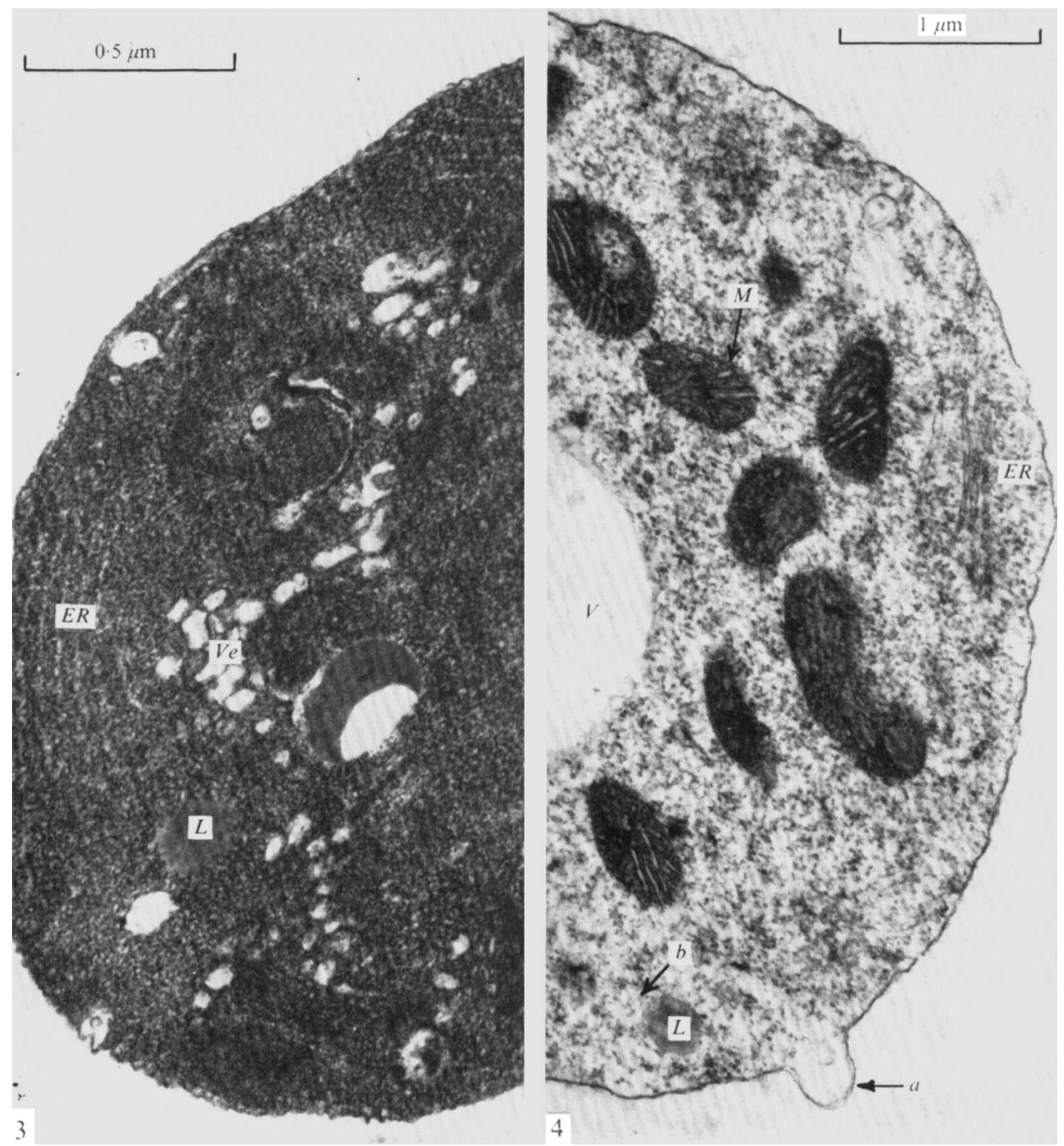

Fig. 3. Part of a protoplast released from mycelium during first hour of enzyme incubation. The cytoplasm contains a high density of ribosomes. Small vesicles occur both near the plasmalemma and deeper in the cytoplasm.

Fig. 4. Part of a protoplast released from mycelium during second hour of enzyme incubation and exhibiting diffuse cytoplasm and large central vacuole. Arrow $(a)$ indicates outpushing of the plasmalemma. Clusters of transparent granules (arrowed $b$ ) may be glycogen. 

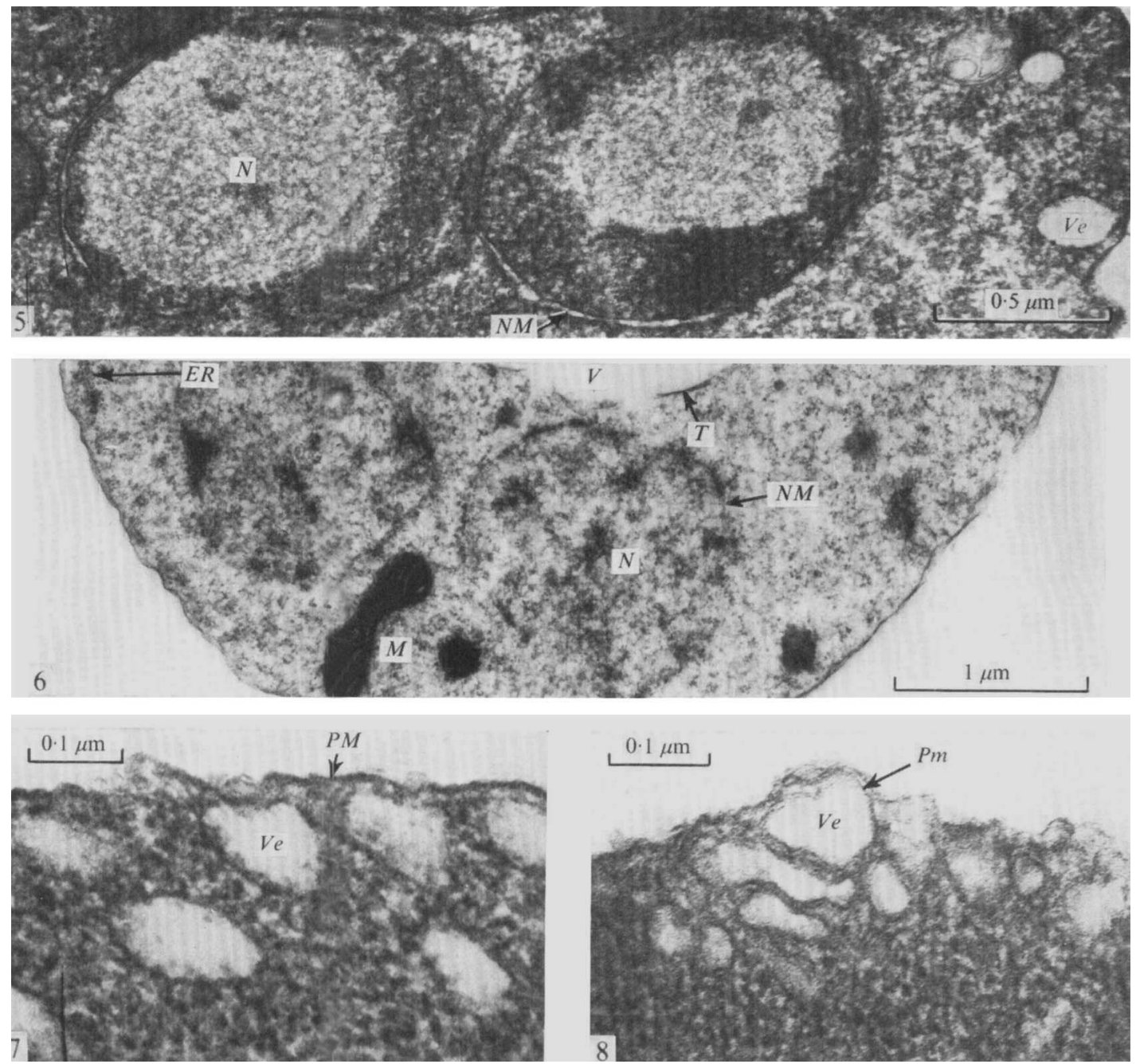

Fig. 5. Section of protoplast released during first hour of enzyme incubation and exhibiting two nuclei with darker regions at their periphery, dense ribosome rich cytoplasm, and small peripheral vesicles.

Fig. 6. Section of protoplast released during second hour of enzyme incubation and exhibiting large central vacuole with broken tonoplast, diffuse cytoplasm and two nuclei with interrupted nuclear membrane.

Fig. 7. Membrane-bounded vesicles located beneath the plasmalemma of an early release protoplast.

Fig. 8. Group of membrane-bounded vesicles closely adpressed to the plasmalemma with resulting corrugation of the protoplast surface.

Some protoplasts contained one or more large vacuoles, with occasional electronopaque or membranous inclusions. (Fig. I, 4). The vacuoles were limited by a tonoplast (Fig. 2) which was sometimes torn away from the cytoplasm. Small membrane-bounded vesicles were also apparent in some protoplasts (Fig. 3, 5, 7, 8).

Two types of protoplasts could be distinguished. The first was characterized by early release from a mycelium incubated with lytic enzyme, and by their small diameter, dense 

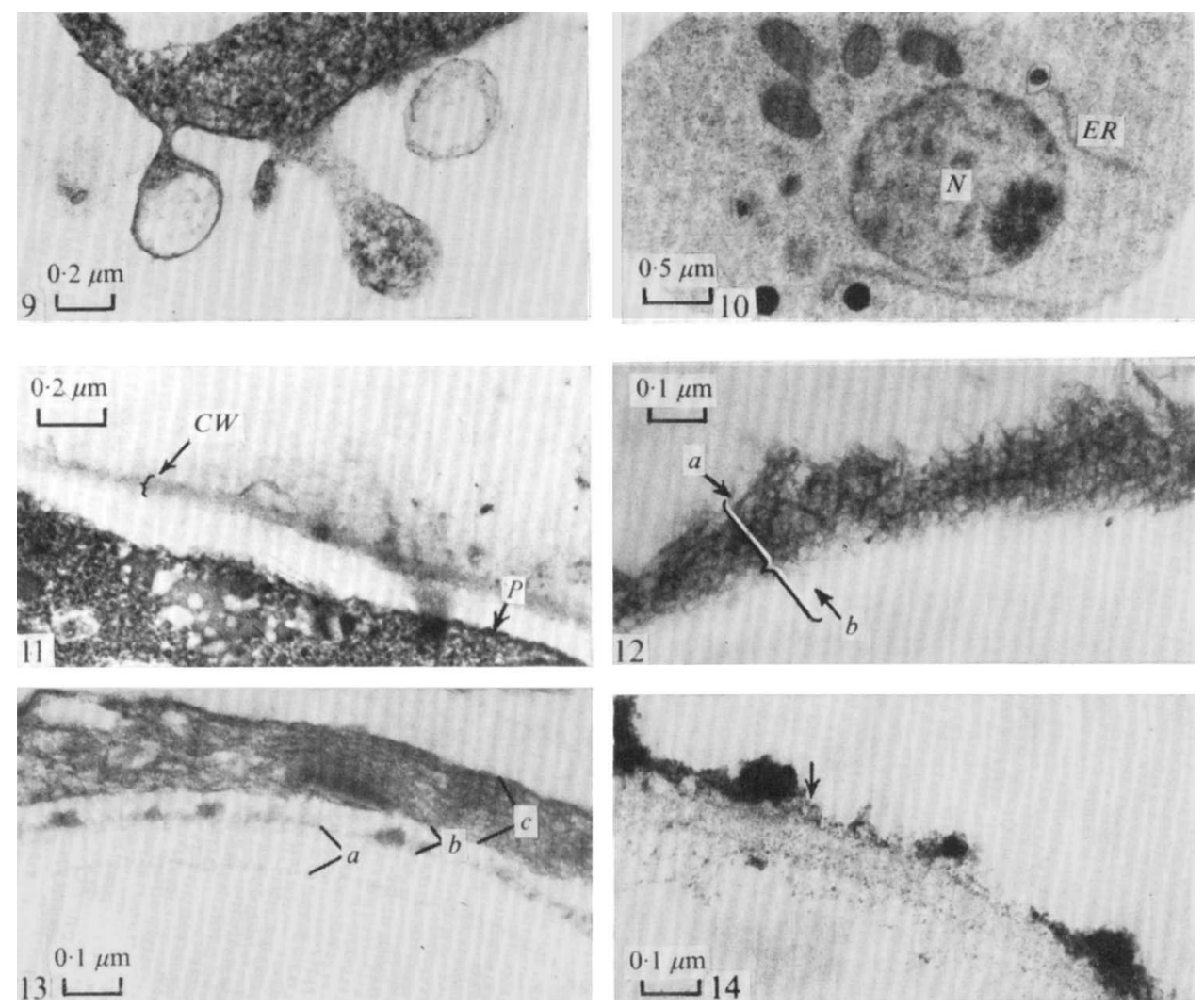

Fig. 9. Region of protoplast plasmalemma exhibiting outpushing. This may lead to the production of 'subprotoplasts'.

Fig. 10. Protoplast exhibiting nucleus with densely stained polar region and cytoplasm with sparse endoplasmic reticulum.

Fig. I I. Portion of lightly stained wall of young plasmolysed hypha of Aspergillus nidulans. Thickness of wall shown by bracket.

Fig. I2. Portion of mature wall of plasmolysed hypha showing an outer fibrous layer (arrowed $a$ ) and an inner electron-translucent layer (arrowed $b$ ). Wall thickness is shown in brackets.

Fig. 1 3. Portion of old wall of plasmolysed hypha exhibiting an inner electron-translucent layer (a), middle layer with densely staining regions $(b)$ and outer fibrous layer $(c)$.

Fig. I4. Portion of mature wall after enzymatic degradation, and showing the removal of parts of the outer fibrous layer (arrowed).

ribosome-rich cytoplasm and the presence of small vesicles (Fig. I, 3). The second type of protoplast, released later during incubation were larger, vacuolate, and had diffusely granular cytoplasm with fewer ribosomes. (Fig. I, 4). At later stages during mycelial incubation release of progressively larger protoplasts was observed.

These findings (Table $\mathrm{r}$ ) confirm observations of size and vacuolation of protoplasts in an earlier report (Peberdy \& Gibson, 1971) and it is postulated that the difference in fine structure and size results from the separate origin of protoplasts. Some protoplasts were released from young hyphal tips early during incubation and others, released later, originated from regions progressively further from the apex. The difference in the time of release of protoplasts may have been caused by differences in thickness of the hyphal walls, which 
Table I. Observations on protoplasts released from o to 3 h during incubation of Aspergillus nidulans PI29 mycelium with Streptomyces venezulae RA lytic enzyme

\begin{tabular}{|c|c|c|}
\hline $\begin{array}{l}\text { Time of } \\
\text { release }(h)\end{array}$ & $\begin{array}{l}\text { Light-microscopic } \\
\text { observation of hyphae }\end{array}$ & $\begin{array}{c}\text { Protoplast } \\
\text { diameter }(\mu \mathrm{m})\end{array}$ \\
\hline$O$ to $I$ & Swelling of tips & $4 \cdot 1$ to $5 \cdot 5$ \\
\hline 1 to 2 & $\begin{array}{l}\text { Swelling of } \\
\text { distal regions }\end{array}$ & $4 \cdot I$ to $8 \cdot 25$ \\
\hline 2 to 3 & Fragmentation & $4 \cdot 1$ to $13 \cdot 75$ \\
\hline
\end{tabular}

Ultrastructural observations of protoplasts

Non-vacuolate. Dense granular cytoplasm. Small vesicles underlying the plasmalemma.

Vacuolate. Cytoplasm diffusely granular. Small vesicles absent.

Larger vacuole. Other characteristics as in 1 to $2 \mathrm{~h}$ protoplasts.

increases with distance from the hyphal tip. Micrographs of young regions of Aspergillus nidulans hyphae (Fig. II) showed the wall as a weakly stained layer approximately $0.07 \mu \mathrm{m}$ thick and with little structure. In other regions which may have been mature, the wall was two layered (Fig. I2) with an inner electron-translucent layer and an outer tightly woven fibrous layer of variable depth and an overall wall thickness of $0.2 \mu \mathrm{m}$. The two-layered structure is similar to that of Neurospora crassa (Shatkin \& Tatum, I959). The fibrous coat was often observed slightly separated from the inner layer and seemed to be detached easily. Some sections of mature hyphae showed the wall to have three layers with an overall thickness of $0.25 \mu \mathrm{m}$ (Fig. 13 ). The innermost layer was almost electron-translucent and was bounded by a layer containing electron-opaque regions. The outermost layer showed tightly packed fibrils which appeared to be arranged parallel in transverse section. Sections of hyphae after incubation with lytic enzyme demonstrated the degradation of the fibrous layer (Fig. I4) and it is assumed that this is removed before the inner layer can be attacked and the protoplast released. Sagara (I969) found that the solubility of walls of hyphae of Geotrichum candidum by gut juice from Helix pomatia decreased with age of the hyphae.

In filamentous fungi growth involves extension at the hyphal tip with associated wall synthesis (Aronson, 1965; Robertson, 1965; Zalokar, 1965). Studies in many fungi (e.g. Marchant et al. 1967; McClure, Park \& Robinson, 1968; Girbardt, 1969; Grove \& Bracker, I970; Bracker, I97I; Heath, Gay \& Greenwood, I97I) have demonstrated that the formation of new wall is accompanied by the presence of cytoplasmic membrane-bounded vesicles beneath the plasmalemma. The occurrence of small vesicles in protoplasts released early in incubation (Fig. 3, 7, 8) may therefore suggest that those protoplasts originated from the apex of a hypha. Protoplasts released later, probably from older regions of the hyphal filament, showed the presence of vacuoles and absence of small vesicles (Fig. I, 4). The presence of transparent glycogen granules further supports the opinion that these protoplasts originate from distal hyphal regions where glycogen is usually found (Zalokar, 1965). The ability of protoplasts of Aspergillus nidulans PI29 to regenerate (Peberdy \& Gibson, 197I) further suggests that the vesicles may be involved in wall formation and work to discover if wall regeneration is a feature of one or both types of protoplast is in progress. Alternatively the small vesicles may fuse to form the larger vacuoles. Isolation and chemical analysis of these organelles is therefore required to confirm their nature and function.

The relative high density of ribosomes and absence of vacuoles in protoplasts released early in incubation are probably caused by cytoplasmic streaming from the older regions of the hypha to the tip where most of the synthetic activity is located (Zalokar, I959). It is generally considered (Buller, I958) that cytoplasmic streaming is caused by vacuolation of distal hyphal regions forcing cytoplasm towards the apex, thus the tips remain in a_constantly 
turgid state without vacuoles. These considerations would explain the differences in ribosome density and cytoplasmic vacuolation (Fig. I, 3, 4) already described in protoplasts released early and later during incubation with lytic enzyme.

We thank the Science Research Council for a Research Studentship to R.K.G. and a research grant B/SR/8434 to J.F.P. also Mr B. V. Case for photographic work.

\section{REFERENCES}

Aronson, J. M. (1965). The cell wall. In The Fungi, vol. I, pp. 49-76. Edited by G. C. Ainsworth \& A. A. Sussman. New York: Academic Press.

BRACKER, C. E. (1971). Cytoplasmic vesicles in germinating spores of Gilbertella persicaria. Protoplasma 72, $381-397$.

Buller, A. R. H. (1958). Researches on Fungi, vol. v, ch. II. New York: Hafner Publishing Co.

CAMPBELL, C. K. (1970). Fine structure of vegetative hyphae of Aspergillus fumigatus. Journal of General Microbiology 64, 373-376.

Darling, S., Theilade, J. \& Birch-Anderson, A. (I969). Kinetic and morphological observations on Saccharomyces cerevisiae during spheroplast formation. Journal of Bacteriology 98, 797-810.

Garcia Lop ez, M. D., Rodriguez Aguirre, M. J., Uruburu, F. \& Villanueva, J. R. (1967). Characterization of the lytic Streptomyces RA as a new strain of Streptomyces venezuelae. Antonie van Leeuwenhoek 33, 315-323.

Girbardt, M. (1969). Die Ultrastruktur der Apikalregion von Pilzhyphen. Protoplasma 67, 413-44I.

Grove, S. N. \& Bracker, C. E. (1970). Protoplasmic organization of hyphal tips among fungi: vesicles and spitzenkörper. Journal of Bacteriology 104, 989-1009.

HAWKeR, L. E. \& AввоTT, P. MCV. (1963). An electron microscope study of maturation and germination of sporangiospores of two species of Rhizopus. Journal of General Microbiology 32, 295-298.

HAWKeR, L. E. \& HENDY, R. J. (1963). An electron microscope study of germination of conidia of Botrytis cinerea. Journal of General Microbiology 33, 43-46.

Havelková, M. (1966). A comparative study of submicroscopic structures of protoplasts of various yeast species. Folia microbiologica, Praha II, 453-458.

HeAth, I. B., Gay, J. L. \& Greenwood, A. D. (1971). Cell wall formation in the saprolegniales: cytoplasmic vesicles underlying developing walls. Journal of General Microbiology 65, 225-232.

KaWAKami, N. (196I). Thread-like mitochondria in yeast cells. Experimental Cell Research 25, 179-18r.

Kuster, E. \& Williams, S. T. (1964). Selection of media for isolation of Streptomyces. Nature, London 202, 928-929.

McCluRe, W. K., Park, D. \& Robinson, P. M. (I968). Apical organisation in the somatic hyphae of fungi. Journal of General Microbiology 5o, I77-182.

MaNocha, M. S. (I968). Electron microscopy of the conidial protoplasts of Neurospora crassa. Canadian Journal of Botany 46, $1561-1564$,

Marchant, R., Peat, A. \& Banbury, G. H. (1967). The ultrastructural basis of hyphal growth. New Phytologist 66, 623-629.

MoORe, R. T. \& MCAlear, J. H. (1963). Fine structure of mycota: 9. Fungal mitochondria. Journal of Ultrastructure Research 8, I44-153.

NEČAS, O. (1964). Mechanism of regeneration of yeast protoplasts. III. Electron microscopy of growing protoplasts. Folia microbiologica, Praha II, 371-377.

Peberdy, J. F. \& Gibson, R. K. (I97I). Regeneration of Aspergillus nidulans protoplasts. Journal of General Microbiology 69, 325-330.

Prusso, D. C. \& Wells, K. (1967). Sporobolomyces roseus. I. Ultrastructure. Mycologia 59, 337-348.

REYNOLDS, E. S. (1963). The use of lead citrate at high $\mathrm{pH}$ as an electron-opaque stain in electron microscopy. Journal of Cell Biology 17, 208-213.

RoBERTSON, N. F. (1965). The mechanism of cellular extension and branching. In The Fungi, vol. 1, pp. 613623. Edited by G. C. Ainsworth \& A. A. Sussman. New York: Academic Press.

RoullleR, C. (1960). Physiological and pathological changes in mitochondrial morphology. International Review of Cytology 9, 227-292. 
SAGARA, Y. (1969). Studies of protoplasts of Geotrichum candidum: mechanism of formation of protoplasts and their physiological and morphological properties. Tokushima Journal of Experimental Medicine I6, $56-69$.

Shatkin, A. J. \& TAtum, E. L. (1959). Electron microscopy of Neurospora crassa mycelia. Journal of Biophysical and Biochemical Cytology 6, 423-426.

StREIBLOVÁ, E. (I968). Surface structure of yeast protoplasts. Journal of Bacteriology 95, 700-707.

TANaKa, K. \& Yanagita, T. (1963). Electron microscopy of ultra-thin sections of Aspergillus niger. I. The fine structure of hyphal cells. Journal of General and Applied Microbiology 9, 101-I 18.

Uruburu, F., Elorza, V. \& Villanueva, J. R. (1968). The fine structure of yeast regenerating protoplasts. Journal of General Microbiology 5I, I95-I98.

ZALOKAR, M. (1959). Growth and differentiation of Neurospora hyphae. American Journal of Botany 46, 602-610.

ZALOKAR, M. (1965). Integration of cellular metabolism. In The Fungi, vol. 1, pp. 377-426. Edited by G. C. Ainsworth \& A. A. Sussman, New York: Academic Press. 